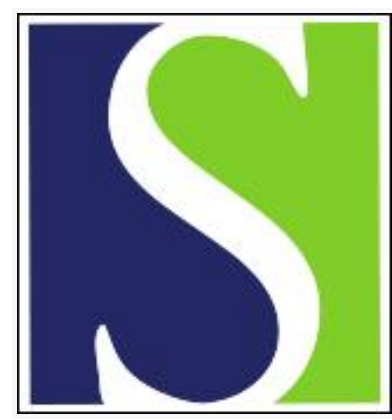

Scand J Work Environ Health 2006;32(3):198-203

https://doi.org/10.5271/sjweh.999

Issue date: 30 Jun 2006

Relationship between hand-arm vibration exposure and onset time for symptoms in a heavy engineering production workshop

by Burström L, Hagberg M, Lundström R, Nilsson T

Affiliation: National Institute for Working Life, Department of Work and the Physical Environment, PO Box 7654 SE-907 13 Umeå, Sweden. lage.burstrom@niwl.se

Key terms: accumulate; disorder; engineering production workshop; exposure; hand-arm vibration; incidence; neurological complaint; onset time; standard; vascular symptom

This article in PubMed: www.ncbi.nlm.nih.gov/pubmed/16804622

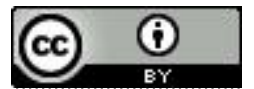




\title{
Relationship between hand-arm vibration exposure and onset time for symptoms in a heavy engineering production workshop
}

\author{
by Lage Burström, PhD, ${ }^{1}$ Mats Hagberg, PhD, ${ }^{2}$ Ronnie Lundström, PhD, ${ }^{3}$ Tohr Nilsson, PhD ${ }^{4}$
}

\begin{abstract}
Burström L, Hagberg M, Lundström R, Nilsson T. Relationship between hand-arm vibration exposure and onset time for symptoms in a heavy engineering production workshop. Scand J Work Environ Health 2006;32(3):198203.

Objectives This study examined onset time for reported vascular and neurological symptoms in relation to the vibration load in a group of workers exposed to vibration.

Methods Information on the self-stated year for the first occurrence of symptoms was collected by means of questionnaires. During interviews data were obtained on self-stated estimations of daily exposure time, type of tool, and number of months or years with different exposures. The estimations of the vibration magnitudes of exposure were based on conducted measurements. From these data, the individual vibration exposure at the time of onset of symptoms was calculated.

Results The incidence was 25.6 and 32.9 per 1000 exposure years for vascular and neurological symptoms, respectively, in the group of workers. The first onset of symptoms appeared after an average of 12 years of exposure. For the workers, the symptoms of vascular or neurological disorders started after about the same number of exposure years. The calculated accumulated acceleration correlated best with the onset time of symptoms. Conclusions It was concluded that, since the workers' exposure to vibration was below the action level established in the European vibration directive, the results suggest that the action level is not a safe level for avoiding vascular and neurological symptoms.
\end{abstract}

Key terms accumulate; disorder; incidence; neurological complaint; standard; vascular symptom.

Occupational work with vibrating handheld power tools is associated with an increased occurrence of symptoms and signs of vascular, neurological, and musculoskeletal disorders of the upper extremities (1). Collectively these disorders are referred to as the hand-arm vibration syndrome. The vascular component of the handarm vibration syndrome is represented by a secondary form of Raynaud's phenomenon and is known as vibration-induced white finger (1). The neurological component is characterized by a peripheral, diffusely distributed neuropathy with predominant sensory impairment (2). The prevalence rate of these vascular and neurological symptoms among vibration-exposed workers varies from a few percent to up to one hundred percent $(3,4)$. Several epidemiologic studies have also been conducted to establish exposure-response relationships between vibration dose and the effect represented by symptoms expressed in terms of latency period-the ex- posure time before the onset of symptoms for selected percentiles of an exposed population $(5,6)$.

Today the risk assessments for hand-transmitted vibration are mainly based on international standard ISO 5349-1 (7). In the annex of the standard, an exposureresponse relationship has been included that is based on the daily vibration exposure, expressed as 8-hour energy-equivalent frequency-weighted acceleration and the years of vibration exposure experienced before vascular symptoms for $10 \%$ of an exposed population. The reliability of the exposure-response relationship has been a matter of debate in the last decades since studies showing both the over- and underestimation of the predicted risk have been reported $(1,4,5,8,9)$. Since the standard only covers vascular symptoms, various authors have discussed the possible form of an exposureresponse relationship for neurological symptoms (10, 11). A few investigators have also suggested that

$1 \quad$ National Institute for Working Life, Department of Work and the Physical Environment, Umeå, Sweden.

2 Sahlgrenska University Hospital, Department of Occupational and Environmental Medicine, Göteborg, Sweden.

3 University Hospital of Northern Sweden, Department of Occupational and Environmental Medicine, Umeå, Sweden.

4 Sundsvall Hospital, Department of Occupational and Environmental Medicine, Sundsvall, Sweden.

Reprint requests to: Dr L Burström, National Institute for Working Life, Department of Work and the Physical Environment, PO Box 7654 SE-907 13 Umeå, Sweden. [E-mail: lage.burstrom@niwl.se] 
neurological symptoms would likely appear earlier than vascular symptoms, a situation that probably reflects different pathogenic mechanisms $(5,10,12-14)$. However, no clear relationship has been found between outcome and vibration dose on an individual basis (5). Clinical and epidemiologic studies have also reported that workers exposed to hand-transmitted vibration may be affected with neurological and vascular symptoms separately or simultaneously (1).

Therefore, this study focused on increasing knowledge about the relationship between hand-arm vibration exposure and the onset time (latency period) for vascular and neurological symptoms by investigating a group of workers exposed to vibration in a heavy engineering production workshop.

\section{Study population and methods}

\section{Study population and cohort information}

The study was conducted on a cohort of workers (all men) who produce paper and pulp-mill machinery in northern Sweden. These workers have also been included in a larger cohort earlier described by Nilsson et al (9). In this study, however, only workers employed in the specific department manufacturing large paper and pulp-mill machinery components were included. Their worktask consists mainly of welding, plating, and grinding iron and stainless steel. The study started in 1987 and was followed-up in 1992 and 1997. In 1987, 68 workers [mean age 32.3 (SD 9.7) years] listed on the employee rosters were included in the study population. In 1992, the number of workers was 77 [mean age 35.5 (SD 10.5) years], and in 1997 the cohort consisted of 74 workers [mean age 37.3 (SD 9.7) years]. Altogether 87 workers have been or are included in the cohort, of which 55 participated at all three occasions. After 1987, 14 new workers were recruited. In 1992, the loss to follow-up was 5.9\% (4 workers). In 1997, the loss to follow-up was $11.7 \%$ (9 workers).

\section{Exposure assessment}

The assessment of vibration exposure was made under normal work conditions by measuring the intensity of vibration and the exposure time for each of the air-powered tools in use. The tool vibration intensity was measured in accordance with ISO $5349(7,15)$ during 1987, 1992, and 1997 on all types of tools and at all relevant job stations. These measurements also included measurements of tools used in the department in earlier periods. In 1987, the measurements were conducted on a total of 36 handheld vibrating tools, in 1992 on 57 tools, and in 1997 on 114 tools. The number of tools included during each investigation period varied between $50 \%$ and $90 \%$ of the total amount of tool use in the department. The field measurements were carried out for at least one representative work cycle; therefore, the registration time varied between 2 and 45 minutes.

The equipment for measuring the intensity of vibration acceleration consisted of miniature accelerometers (Endevco 226 C or 2226 C, Endevco Corp, San Juan, CA, USA) and charge amplifiers (Brüel \& Kjaer 2635, Brüel \& Kjær, Nærum, Denmark). The accelerometers were attached with glue to a strong hose clamp provided with a small piece of metal. The hose clamp was mounted on the tools as close as possible to the operator's hand. This method provides a means for simultaneous measurement in three directions. The signals from the accelerometers were recorded on tape (Brüel \& Kjaer 7500 or Sony PC 204A, Sony Corp, Tokyo, Japan) within the frequency range of at least 2 to 5000 Hz. Just before and after the measurements, the measuring equipment was calibrated with an accelerometer calibrator (Brüel \& Kjaer 4291 or 4294). The reason for this double calibration was to ensure that no error had occurred in the measuring equipment during the measurements. The calibration signals were also registered with the recorder. The data analysis of vibration acceleration consisted of a determination, in each of the three measurement directions, of the frequency-weighted vibration level in accordance with ISO 5349 using a dual channel analyzer (Brüel \& Kjaer 2133).

The results from conducted measurements, in the form of the mean value of the frequency-weighted acceleration for grinders, hammers, and other tools (drills, die grinders, saws, screw drivers) are presented in table 1 for the different investigation years. Over the study period, the mean value of the frequency-weighted

Table 1. Frequency-weighted acceleration $\left(\mathrm{m} / \mathrm{s}^{2}\right)$ of studied handheld vibrating tools for the three investigation periods.

\begin{tabular}{|c|c|c|c|c|c|c|c|c|c|}
\hline \multirow{3}{*}{$\begin{array}{l}\text { Investigation } \\
\text { year }\end{array}$} & \multicolumn{9}{|c|}{ Type of tool } \\
\hline & \multicolumn{3}{|c|}{ Grinders } & \multicolumn{3}{|c|}{ Hammers } & \multicolumn{3}{|c|}{ Others } \\
\hline & $\mathrm{N}$ & Mean & SD & $\mathrm{N}$ & Mean & SD & $\mathrm{N}$ & Mean & SD \\
\hline 1987 & 17 & 5.5 & 2.1 & 16 & 10.3 & 3.4 & 3 & 1.5 & 1.8 \\
\hline 1992 & 36 & 5.0 & 2.9 & 16 & 12.0 & 3.7 & 5 & 3.5 & 2.0 \\
\hline 1997 & 74 & 4.2 & 2.0 & 32 & 8.7 & 3.9 & 8 & 4.2 & 3.1 \\
\hline
\end{tabular}


acceleration was $4-6 \mathrm{~m} / \mathrm{s}^{2}$ for the grinders, $9-12 \mathrm{~m} / \mathrm{s}^{2}$ for the hammers, and $1-4 \mathrm{~m} / \mathrm{s}^{2}$ for the other tools.

The daily vibration-exposure time was assessed by both subjective assessments and by an objective measurement of the time used for each type of handheld tool. The objective measurements were carried out by observation. The observer noted the kind of tool the operator was handling, whether the machine was working, and which hand was exposed for each minute during an observation time of between 45 and 180 minutes. For each investigation year, between 12 and 18 male workers were observed during active worktime that covered different parts of the workday.

The subjective assessments of daily exposure time were collected in the following three ways: diary, questionnaire, and interview. In the diary, the workers were asked to note every evening the handheld tools they used during the day (minutes). They also noted which type of tool was used and what type of work they had done. These diaries were used for two weeks, and between $65 \%$ and $80 \%$ of the workers completed this investigation during each study period. All of the participants also answered a questionnaire on vibration exposure, with which information was collected about the onset of vibration exposure, exposure, duration of exposure per day, and the number of years of such exposure. Information was collected about the self-stated year for the first occurrence of vascular and neurological symptoms. During 1992 and 1997, about 72\% of the workers were interviewed for information about the number of years they worked, the type of work they performed, the type of exposure they experienced, and the duration of exposure per day. The results from the conducted studies (16) of the daily exposure time showed a large individual deviation, but also evidence for good agreement between the estimated and measured exposure time on a group basis. Based on all three estimates, the mean total daily exposure time for vibrating tools was about 105 minutes in 1987, 70 minutes in 1992, and about 55 minutes in 1997. From 1987 to 1997, the 8-hour energyequivalent acceleration decreased from $4.5 \mathrm{~m} / \mathrm{s}^{2}$ to 2.9 $\mathrm{m} / \mathrm{s}^{2}$ (17). Exposure to vibration is mainly the result of using grinders and hammers. These two types of tools correspond to about $85-95 \%$ of the total daily use of handheld tools.

The individual vibration exposure before the onset of the symptoms was calculated both as energy-equivalent acceleration for the worktime and as accumulated vibration exposure (16). The energy-equivalent acceleration for each person was estimated according to the following formula:

$$
a_{e q v}=\left\langle\frac{1}{T} \cdot \sum_{i=1}^{n}\left[\left(a_{h, w, W o r k_{i}}\right)_{e q v, i(8)}\right]^{2} \cdot t_{i}\right\rangle^{1 / 2}\left[\mathrm{~m} / \mathrm{s}^{2}\right],
$$

equation 1 where $a_{e q v}=$ the 8-hour energy-equivalent acceleration until symptom $\left[\mathrm{m} / \mathrm{s}^{2}\right],\left(a_{h, w, W o r k}\right)_{\text {eqv,i(8) }}=$ the 8 -hour energy-equivalent acceleration during $i$ th time period for $\operatorname{Work}_{i}\left[\mathrm{~m} / \mathrm{s}^{2}\right], t_{i}=$ the duration of the acceleration $\left(a_{h, w, W_{0 r k}}\right)_{\text {eqv }, i(8)}$ [year], $T=$ the total worktime until symptom [year], and $n=$ the total number of jobs.

The accumulated vibration acceleration for each individual has been estimated using the following formula:

$$
a_{\text {cum }}=\sum_{i=1}^{n}\left(a_{h, w, W o r k}\right) \cdot t_{i}\left[\mathrm{mh} / \mathrm{s}^{2}\right], \quad \text { equation } 2
$$

where $a_{\text {cum }}=$ the accumulated vibration acceleration until symptom $\left[\mathrm{mh} / \mathrm{s}^{2}\right],\left(a_{h, w, W o r k}\right)=$ the vibration acceleration during $i$ th time period for Work $\left[\mathrm{m} / \mathrm{s}^{2}\right]$, $t_{i}=$ the duration of the acceleration $\left(a_{h, w, W_{0 r k}}\right)$ for Work $_{i}$ [hours/days - days/year - year (h); workdays per year was set to 200], and $n=$ the total number of jobs.

\section{Statistical analyses}

Computer SAS software (SAS Institute, Cary, NC, USA) was used for the statistical analysis. The occurrence of vascular symptoms was defined as the respondent having answered "yes" to the question "Do you have white (pale) fingers of the type that appears when exposed to damp and cold weather?" and also having marked the affected fingers on a sketch and having reported the year of onset. For the definition of neurological symptoms, the respondent had to answer "yes" to the question "Do you experience numbness/tingling during the night?", mark a sketch of the affected areas, and report the year of onset. The incidence calculation included all of the workers without symptoms at the start of the job. Time to event was computed as the number of years to the onset from the age of 16 years (job start). The time to the first occurrence of symptoms was regardless of side (right or left hand). Participants who did not become a case during the study contributed with a person-time corresponding to the period between the job start and when they filled out their last follow-up questionnaire in 1997. For the analyses of the differences in the correlations, the Olkin and Siotani method was used (18).

\section{Results}

Among the 87 workers, 53 (61\%) reported vascular or neurological symptoms or both. In the cohort, 34 (39\%) employees reported vascular symptoms, and $41(47 \%)$ reported neurological symptoms. Twenty-two (25\%) workers stated that they suffered from both types of symptoms; $12(14 \%)$ stated they suffered from only vascular symptoms; 19 (22\%) stated they suffered from only neurological symptoms. After the study started in 
1987,19 of the vascular cases and 22 of the neurological cases were reported. The incidence was 25.6 per 1000 exposure years [95\% confidence interval $(95 \% \mathrm{CI})$ 19.1-38.5] for vascular symptoms and 32.9 per 1000 exposure years (95\% CI 23.6-44.6) for neurological symptoms.

On the average, the first symptoms started after about 12 years of exposure. Vascular symptoms developed after a mean period of 11.6 (SD 6.8) years of exposure (95\% CI 2.7-26.4), while the neurological symptoms appeared after a mean period of 13.0 (SD 7.7) exposure years (95\% CI 2.0-29.0) (table 2). The difference in the onset time was not significant. The exposure time varied between 5500 and 7200 hours before the symptoms became manifest. The energy-equivalent daily acceleration exposure and the accumulated vibration exposure were found to be $2.1-2.5 \mathrm{~m} / \mathrm{s}^{2}$ and 38200 $45300 \mathrm{mh} / \mathrm{s}^{2}$, respectively.

Figure 1 shows the relation between the percentage of the study population with different symptoms (vascular or neurological) and years of exposure. Figure 2 shows the corresponding relation for the accumulated acceleration $\left(\mathrm{mh} / \mathrm{s}^{2}\right)$. In addition, the figures show the same relation for the first symptom, either vascular or neurological.

For $10 \%$ of the working group, the first symptom (either vascular or neurological) appeared at about 5 years of exposure (figure 1). The onset time for vascular, as well as neurological, symptoms was 7 exposure years. Estimations of exposure years, according to ISO 5349-1, showed that, with the actual vibration exposure, the prediction for the $10 \%$ prevalence of vibration-induced white finger (vascular symptoms) among workers is between 12 and 14 years. Figure 2 shows that the first symptom (either vascular or neurological) appeared at an accumulated acceleration of about $8000 \mathrm{mh} / \mathrm{s}^{2}$ for $10 \%$ of the cohort.

The best correlation between the numbers of years before the onset of vascular or neurological symptoms and vibration load was found to be the accumulated acceleration ( $R=0.62$ and $R=0.47$, respectively). The exposure time expressed in hours of work with vibrating handheld tools was also correlated with the onset time, but with a lower, but not significant, degree of explanation of the variance $(R=0.51$ and $R=0.41$, respectively). The daily equivalent acceleration had a very low relation to the number of years before onset, and the correlation was significantly lower $(\mathrm{P}$-value $=$ 0.0097) than the other correlations.

\section{Discussion}

The results of this study may have been subjected to several sources of bias, in particular due to the healthy
Table 2. Onset time for vascular and neurological symptoms, as well as the daily equivalent and accumulated acceleration to onset.

\begin{tabular}{lccccc}
\hline Group & $\begin{array}{c}\text { Work- } \\
\text { ers } \\
\text { (N) }\end{array}$ & $\begin{array}{c}\text { Mean } \\
\text { onset } \\
\text { time } \\
\text { (years) }\end{array}$ & $\begin{array}{c}\text { Mean } \\
\text { expo- } \\
\text { sure } \\
\text { time } \\
\text { (h) }\end{array}$ & $\begin{array}{c}\text { Mean } \\
\text { daily } \\
\text { equi- } \\
\text { valent } \\
\text { accel- } \\
\text { eration } \\
\text { (m/s) }\end{array}$ & $\begin{array}{c}\text { Mean } \\
\text { accu- } \\
\text { mulated } \\
\text { eration } \\
\left(\mathrm{mh} / \mathrm{s}^{2}\right)\end{array}$ \\
\hline Vascular symptoms & & & & & \\
Neurological symptoms & 41 & 11.6 & 6100 & 2.1 & 38600 \\
First symptom & 13.0 & 5700 & 2.3 & 41600 \\
Both symptoms & 22 & 11.9 & 5900 & 2.3 & 40100 \\
Only vascular symptoms & 12 & 10.9 & 5500 & 2.1 & 38200 \\
Only neurological symptoms & 19 & 13.0 & 5900 & 2.1 & 39700 \\
\hline
\end{tabular}

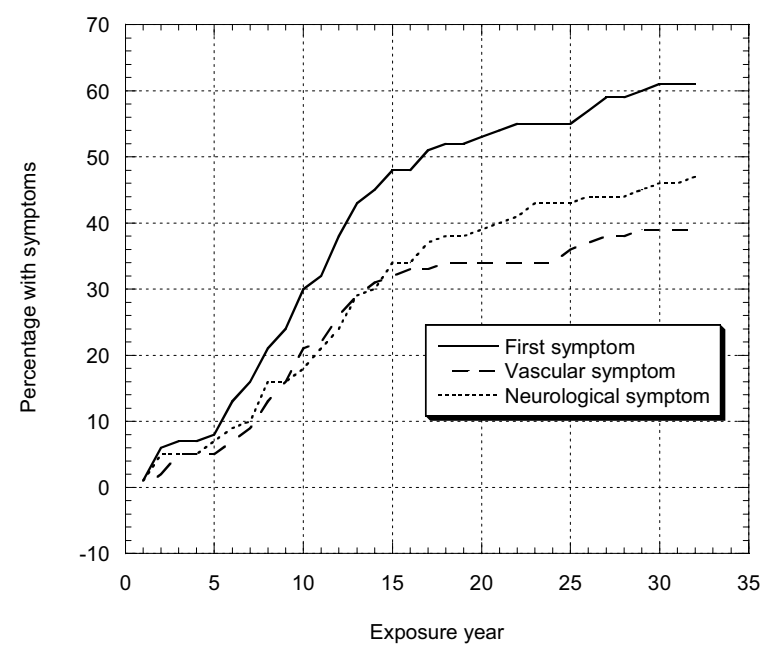

Figure 1. Association between the number of years before the onset of first symptoms (either vascular or neurological)—vascular and neurological symptoms respectively for the cohort.

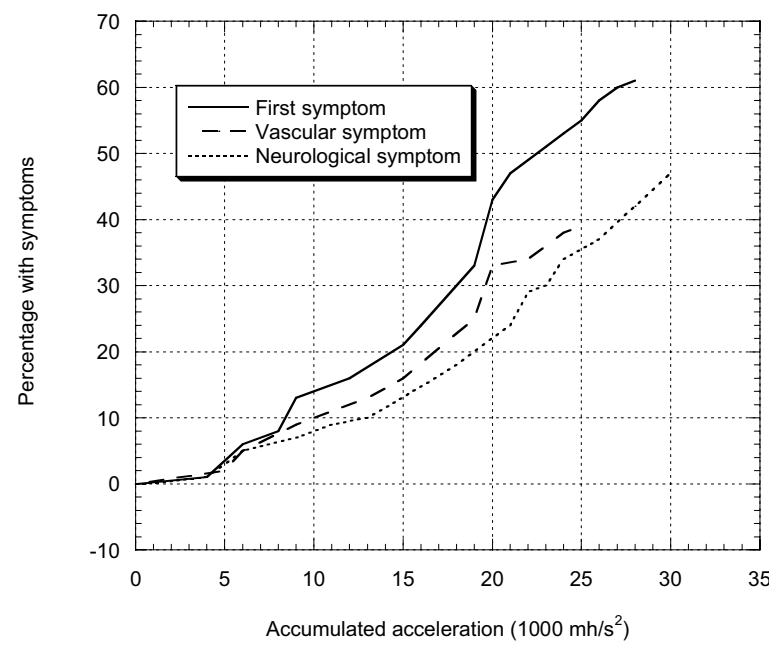

Figure 2. Relationship between the accumulated acceleration (1000 $\mathrm{mh} / \mathrm{s}^{2}$ ) before the onset of first symptoms (either vascular or neurological) — vascular and neurological symptoms respectively for the study population. 
worker effect, information bias, and inaccuracy in the assessment of the exposure. The healthy worker effect, where workers susceptible to vibration left the company, could be estimated to be $4.4 \%$ for vascular symptoms and $7.4 \%$ for neurological symptoms. However, this estimation is based on all workers who were affected by symptoms and left their job for education or other work. Nevertheless, this effect may have led to an underestimation of the prevalence for symptoms in the study group. The prevalence of symptoms in this study was based on self-reported numbers and not verified by the examination of a physician or by the use of objective tests. These reported subjective symptoms could also be circulatory or neurological complaints other than those induced by vibration (5). Although the information has been followed by several questionnaires and interviews, it could still be biased. Moreover, the interviews revealed that occupational exposure to hand-arm vibration usually started at the age of 16 years, when most of the workers were in vocational school. However, there could be inaccuracies in that information. These sources of information bias cannot be quantified. Exposure data were carefully checked using several investigation methods. The information on worktask, year of exposure, type of used handheld tools, exposure time per day, and year was collected in direct interviews of the workers. Since many of the workers had been working for the company for a long time and had worked in a similar job, the given information has been controlled against each other and against the company register. In case of discrepancy, new interviews were carried out. This procedure mainly reduced the errors in the estimation of the exposure time. Furthermore, vibration measurements have been conducted on a sample of handheld tools, as well as on tools previously used in the department. The measurements gave an approximate estimate of the vibration intensity of the tools; however, relatively high variation could be expected because of the maintenance of the machine, grinding wheel, type of work, type of material, and the like. Moreover, the analysis did not take into account possible exposure to vibration from nonoccupational sources. Generally, the accuracy for the estimations of the year of onset, exposure time, and the magnitude of vibration intensity were better for the period after the study (starting in 1987) than before.

In this study, the prevalence of vascular and neurological symptoms among the workers was reported to be $39 \%$ and $47 \%$, respectively. The reported prevalence is high compared with that of unexposed male workers in the general population, for which the point prevalence has been reported to be $<5 \%$ (9) for vascular symptoms and $15 \%$ (19) for neurological symptoms. The prevalence of vascular symptoms among the workers is in agreement with that for other vibration-exposed groups (9), and, moreover, the result agrees with those of other studies in which a higher prevalence was also found for neurological symptoms (20-22). The development of symptoms shows that, within the first 10 years of work with vibration handheld tools, $30 \%$ of the cohort had experienced their first symptoms (either vascular or neurological). Moreover, after 15 years of vibration exposure, one-third of the workforce suffered from vascular or neurological symptoms. These figures are much higher than the corresponding prediction of vibration-induced white finger according to ISO 5349. This study, therefore, supports the view that the ISO 5349 standard underestimates the risk for both of these types of vibration-related symptoms. However, it should be noted that the ISO prediction is based on a group of workers using mainly only one type of vibrating handheld power tool, unlike the circumstances in this study.

The incidence for the studied workers was about 26 for vascular symptoms and 33 for neurological symptoms per 1000 exposure years, the finding indicating that about $6 \%$ of the workers acquired these symptoms every year. This incidence of vascular symptoms is about 5 times higher than that of unexposed workers (23) and comparable with that of other groups of vibration-exposed workers $(21,24)$. For neurological symptoms, no incidence data have been found in the scientific literature. Even though there was a difference in incidence between the two types of symptoms, both types started after about the same number of exposure years. This finding does not agree with the results of studies that suggested that neurological complaints would occur earlier than vascular symptoms $(1,5)$.

The best correlation between the number of years before the onset of vascular or neurological symptoms and vibration load was found to be the lifetime exposure to vibration, a finding which also agrees with those of other studies $(5,6,22)$. Moreover, the results also show that the exposure time expressed in hours of work with vibrating handheld tools also correlated with the onset time, but with a lower degree of explanation of the variance. This finding suggests that vibration magnitude plays a significant role in the prediction of symptoms, and it highlights the necessity for correct vibration exposure estimates. The differences in the correlation between the two types of symptoms could be due to the fact that vascular symptoms tend to be more specific to exposure to hand-arm vibration than neurological complaints since the latter can also originate from other nonvibratory causes, such as biomechanical risks (20).

The workers' mean daily vibration exposure over their lifetimes was found to be below the action level $\left(2.5 \mathrm{~m} / \mathrm{s}^{2}\right)$ established in the European vibration directive (25). Since new cases of workers with vascular and neurological symptoms were recruited, it is important to emphasize that the action level is not a safe level for avoiding these types of symptoms. 


\section{Acknowledgments}

The financial support of the Swedish Council for Work Life Research is gratefully acknowledged.

Special thanks go to Rebecka Vilhelmsson for her statistical analysis.

\section{References}

1. Gemne G. Diagnostics of hand-arm system disorders in workers who use vibrating tools. Occup Environ Med. 1997;54:905 .

2. Nilsson T. Neurological diagnosis: aspects of bedside and electrodiagnostic examinations in relation to hand-arm vibration syndrome. Int Arch Occup Environ Health. 2002;75:5567.

3. Mirbod SM, Yoshida H, Komura Y, Fujita S, Nagata C, Miyashita K, et al. Prevalence of Raynaud's phenomenon in different groups of workers operating hand-held vibrating tools. Int Arch Occup Environ Health. 1994;66:13-22.

4. Bovenzi M, the Italian Study Group on Physical Hazards in the Stone Industry. Hand-arm vibration syndrome and doseresponse relationship for vibration-induced white finger among quarry drillers and stone carvers. Occup Environ Med. 1994;51:603-11.

5. Bovenzi M. Exposure-response relationship in the hand-arm vibration syndrome: an overview of current epidemiology research. Int Arch Occup Environ Health. 1998;71:509-19.

6. Griffin MJ, Bovenzi M, Nelson CM. Dose-response patterns for vibration-induced white finger. Occup Environ Med. 2003;60:16-26.

7. International Organisation for Standardisation (ISO). Mechanical vibration-measurement and evaluation of human exposure to hand-transmitted vibration, part 1: general guidelines. Geneva: ISO; 2001. ISO 5349-1.

8. Griffin MJ. Measurement, evaluation, and assessment of occupational exposures to hand-transmitted vibration. Occup Environ Health. 1997;54:73-89.

9. Nilsson T, Burström L, Hagberg M. Risk assessment of vibration exposure and white fingers among platers. Int Arch Occup Environ Health. 1989;61:473-81.

10. Lundström R, Nilsson T, Burström L, Hagberg M. Exposureresponse relationship between hand-arm vibration and vibrotactile perception sensitivity. Am J Ind Med. 1999;35:456-64.

11. Virokannas H. Dose-response relation between exposure to two types of hand-arm vibration and sensorineural perception of vibration. Occup Environ Med. 1995;52:332-6.

12. Lundström R, Hagberg M, Nilsson T. Dose-response relationship for hand-arm vibration syndrome with respect to sensorineural disturbances among platers and assemblers. In: Dupuis H, Christ E, Sandover DJ, Taylor W, Okada A, editors. Proceedings of the 6th international conference on handarm vibration. Sankt Augustin (Denmark): BIA; 1993. p 86573. Schriftreihe des Hauptverbandes der gewerblichen Berufsgenossenschaften (HVBG).
13. Bylund SH, Burström L, Knutsson A. A descriptive study of women injured by hand-arm vibration. Ann Occup Hyg. 2002;46:299-307.

14. Bovenzi M, Giannini F, Rossi S. Vibration-induced multifocal neuropathy in forestry workers: electrophysiological findings in relation to vibration exposure and finger circulation. Int Arch Occup Environ Health. 2000;73:519-27.

15. International Organisation for Standardisation (ISO). Mechanical vibration-measurement and evaluation of human exposure to hand-transmitted vibration, part 2: practical guidelines for measurement at the workplace. Geneva: ISO; 2001. ISO 5349-2.

16. Burström L, Lundström R, Hagberg M, Nilsson T. Comparison of different measures for hand-arm vibration exposure. Saf Sci 1998;28: 3-14.

17. Burström L, Lundström R, Hagberg M, Nilsson T. Vibration load among workers within a heavy engineering production workshop: a ten-year follow-up. In: Hagberg M, Knave B, Lillienberg L, Westberg H, editors. X2001—exposure assessment in epidemiology and practice. Stockholm: National Institute for Working Life; 2001. Arbete och Hälsa, no 10, p 287-9.

18. Kleinbaum D, Kupper L, Muller K, Nizam A. Applied regression analysis and other multivariable methods. 3rd ed. Pacific Grove (CA): Duxbury Press; 1998.

19. Mirbod SM, Inaba R, Iwata H. Operating vibrating tools and prevalence of subjective complaints in vibration syndrome. Cent Eur J Public Health. 1995;3:97-102.

20. Cherniack M, Morse TF, Brammer AJ, Lundström R, Meyer $\mathrm{JD}$, Nilsson T, et al. Vibration exposure and disease in a shipyard: a 13-year revisit. Am J Ind Med. 2004;45:500-12.

21. Barregård L, Ehrenström L, Marcus K. Hand-arm vibration syndrome in Swedish car mechanics. Occup Environ Med. 2003;60:287-94.

22. Jang JY, Kim S, Park SK, Roh J, Lee TY, Youn JT. Quantitative exposure assessment for shipyard workers exposed to hand-transmitted vibration from a variety of vibration tools. AIHA J 2002;63:305-10.

23. Hagberg M, Burström L, Lundström R, Nilsson T. Prospective versus retrospective incidence of Raynaud's phenomenon and the relation to vibration exposure. In; Reynolds DD, editor. Conference program and proceeding of the 10th International Conference on Hand-Arm Vibration 2004 June 7-11, Las Vegas, Nevada, USA. Las Vegas (CA): University of Nevada, Center for Mechanical \& Environment Systems Technology (CMEST); 2004. p 33-4.

24. Kivekäs J, Riihimäki H, Husman K, Hänninen K, Härkönen $\mathrm{H}$, Kuusela T, et al. Seven-year follow-up of white-finger symptoms and radiographic wrist findings in lumberjacks and referents. Scand J Work Environ Health 1994;20:101-6.

25. European Council. Directive 2002/44/EC of the European parliament and of the Council of 25 June 2002 on the minimum health and safety requirements regarding the exposure of workers to the risks rising from physical gents (vibration) (sixteenth individual Directive within the meaning of Article 16(1) of Directive 89/391/EEC). Off J Eur Communities 2002;L 177:13-9.

Received for publication: 31 August 2005 